\title{
Definition-based Versus Contextualized Vocabulary Learning
}

\author{
Seyyed Mohammad Reza Amirian \\ Hakim Sabzevari University, Iran \\ Email: Sm.amirian@sttu.ac.ir \\ Sakine Momeni \\ Hakim Sabzevari University, Iran \\ Email: Momenis.2010@yahoo.com
}

\begin{abstract}
Ability to infer the meaning of unknown words encountered while reading plays an important role in learners' foreign language word knowledge development. The current study was an attempt to investigate the efficiency of two vocabulary learning procedures, i.e. definition-based (decontextualized) versus contextualized. In the contextualized group there were 53 students of grade one in high school and preuniversity who were taught meaning inferencing strategies in which they read their textbooks, identified unknown words in the texts, and inferred the meanings of the unknown words. There were also another 54 students in the decontextualized group who learnt the new words' translations out of context before a new lesson was taught. The findings of the study revealed that the students in decontextualized group slightly outperformed the contextualized group on the vocabulary post-test. It is concluded that definition-based learning was more effective in improving learner's vocabulary knowledge.
\end{abstract}

Index Terms —incidental vocabulary learning, contextualized learning, definition-based learning

\section{INTRODUCTION}

Second-language vocabulary acquisition viewed previously as a 'victim of discrimination' (Levenston, 1979) is a field of investigation that has seen an explosion of experimental research in the past 25 years along with Meara's (1980) call for redressing the 'neglect' of vocabulary development research. Researchers and experts in the fields of reading comprehension and vocabulary have claimed that "vocabulary knowledge is instrumental in reading comprehension and essential for the application of certain reading strategies, such as inferring meaning from context" (Llinares, Leiva, Cartaya, \& St. Louis, 2008 p. 55).

Snellings, Van Gelderen and De Glopper (2002) maintain that "for fluent language production lexical retrieval is an essential subprocess"(p. 723). It involves selection of lexical concepts whether articulated or written down. Many research findings show that poor vocabulary knowledge leads to incorrect inferences or misunderstanding of the content while reading English materials in their academic studies (Laufer, 2001; Nation, 2001).

Melka (1997) suggests three necessary dimensions for adequately describing a person's vocabulary: the number of words known (vocabulary size or breadth), the amount of knowledge present for each word (depth of knowledge), and how quickly this knowledge can be utilized (automaticity). If these three descriptive dimensions are valid, then there is a clear void in the area of vocabulary testing, since no current test adequately describes these three plans.

Researchers in the domain of vocabulary acquisition also concur with the following two major issues: acquisition through direct instruction of vocabulary (intentional) and incidental vocabulary acquisition through exposure to context (Hulstijn, 2001; Nation, 2001). Intentional vocabulary learning refers to activities that aim at vocabulary development predominantly (Shahrzad \& Derakhshan, 2011) and incidental vocabulary acquisition refers to learning something for example vocabulary as the by-product of something else such as reading for comprehension. The incidental vocabulary learning is not the concern of this paper. This study is concerned with intentional vocabulary learning and teaching.

Whether students be taught individual word meanings directly or in context, which would involve the presentation of the word within a sentence, seems to be an existing debate among language professionals. According to Sternberg (1987; as cited in Paribakht \& Wesche, 1999), even if most vocabulary is learned from context, one should not conclude that this "is the fastest or most efficient way of learning specific vocabulary".

However, the proponents of context-based learning argue that vocabulary learning is more than individual word learning. By learning words in context, the learner acquires not only linguistic knowledge of a word, such as phonetic, syntactic and semantic rules, but also the knowledge of how to use the word properly in a context. They also argue that in a definition-based learning only one definition or synonym or a translation of the word in the native language is given, i.e. the learner becomes familiar with just one meaning of the word and this leads to only a shallow level of word knowledge, and it does not increase comprehension of the text containing the instructed words. 
Nagy (1997) believes that the number of words that can be effectively retrieved is a major limitation of definitionbased learning. He writes:

Those who believe that definition-based instruction makes a major contribution to vocabulary growth must hold to a parsimonious model of the mental lexicon, there must be relatively few words to be learned, and very few meanings per word. Such a model of lexicon therefore must rely very heavily on reference specification, rather than sense selection, to account for contextual variation in meaning. However, such reliance on reference-specification is a two-edged sword. On the one hand, it makes definition-based instruction more plausible by allowing a reduction in the number of definitions that need to be learned. On the other hand, it leads to a discrepancy between the definition and the meaning that a word conveys in any given context (p. 72).

\section{RESEARCH BACKGROUND}

In a study of Hebrew speakers studying EFL, four modes of presentation were compared by Laufer and Shmueli (1997), including lists: (I) words presented in isolation, (2) words in minimal context, i.e., in one meaningful sentence, (3) words in text-context, and (4) words in elaborated text context. Results showed that using simple vocabulary lists can yield better vocabulary retention than relying on lists with more information. Retention gains for word recognition were superior in modes 1 and 2, i.e., when less information or limited context was given about the word and inferior in modes 3 and 4 when more information or extended context was given.

In another study, Mondria (2003) investigated whether a word-learning method in which learners inferred the meaning of unknown words from the context and memorized the meaning ("meaning-inferred method") lead to better retention than("meaning-given method") one in which the meaning of unknown words was given in the form of a translation so that learners could immediately start memorizing. The results were as follows: (a) although both method lead to a similar level of retention, the meaning-inferred method was considerably more time-consuming and therefore less efficient; and (b) there was some level of retention in every stage of the meaning-inferred method, but the learning effect of memorizing was the greatest, and the learning effect of verifying and inferring were somehow the same.

Zaid (2009) undertook a study for the purpose of exploring the effects of the following approaches in vocabulary instruction with 34 Level III College of Languages and Translation students. One approach emphasized direct teaching of the individual meanings for a set of unfamiliar words. The second approach emphasized teaching students to derive word meaning from sentence context, rather than teaching specific meanings. Conducting both Pre-test and post-test he found that both approaches were effective in helping students acquire, retain and further recall the lexical items instructed.

One of the central cognitive processes in reading comprehension is inferencing (Nassaji, 2006). Inferencing has been defined by Brown \& Yule (1983) as the connections that people establish when they try to interpret texts. It relates to a whole understanding of longer pieces of discourse in which context affects reading comprehension. "Therefore, inferencing and meaning-guessing are the product of contextualization"(Zaid, 2009, pp. 56-57).

Nagy (1997) in a discussion of the factors involved in lexical inferencing groups learners based on their knowledge bases into three main categories: linguistic knowledge, world knowledge, and strategic knowledge. The linguistic knowledge category covers students' syntactic knowledge, lexical knowledge, and knowledge of word schema (i.e., knowledge of the possible meanings of the word). The way the learner understands and uses the related domains of knowledge is her world knowledge. Strategic knowledge is knowledge of the actual strategies learners employ while they are inferencing and deducing the unknown lexicon meaning from context. Nagy suggests that strategic knowledge may not be a necessity for the acquisition of the words meaning from context, but that sometimes, while the learner is aware of the existence of new words in the text, he or she can deliberately attempt to induce the meanings of these words from context.

The purpose of this study is to investigate which method of vocabulary learning as delineated above, that is contextualized and decontextualized vocabulary learning suits Iranian high school learners. The significance of the study is that it focuses on the efficacy of the vocabulary learning strategies of Iranian EFL learners, a case which has not received the due attention among researchers and demands experimental studies.

\section{METHOD}

\section{A. Participants}

This study aims to investigate the degree of vocabulary learning in non-context vocabulary presentation versus contextualized word instruction. The participants were 103 female students within the age range of 16-19 years. In order to select these participants, the Oxford Placement Test was administered to 120 learners. The results of the test indicated that the majority of participants $(n=103)$ were at the elementary level who were randomly assigned to two conditions of contextualized and decontextualized vocabulary learning.

\section{B. Procedures}

The contextualized group was taught meaning inference strategies. They were taught how to infer the meanings of the words from the local and global contexts of the lexicon. They were taught the prefixes and suffixes necessary for 
inferencing. They were told that they can ignore the meaning of some words which are not at the center of reading comprehension. They were trained how to deal with cohesive devices, and how to use them for a better understanding of the whole discourse. The decontextualized participants were another school's students with the same proficiency level and age range (i.e., elementary level). They were taught the words out of context. They learnt the words' translations by rote learning before learning the new lesson. Then they got familiar with the words within the reading passages. They could see where and in what situations the new words were used. In order to gain knowledge about the students' proficiency level a multiple choice vocabulary test was given to all 103 students both in contextualized and decontextualized group in the first session of English class. Then, each group received the special treatment specified for that group at the beginning of research. After the treatment period, the same vocabulary test that was given to them before the treatment was administered to both groups to discover which group benefited more from the kind of instruction they got. The results of the study are presented in the following section.

\section{RESULTS}

This study was an attempt to compare the effectiveness of contextualized versus definition-based methods of instruction, as two popular procedures of vocabulary teaching, to EFL high school learners. In order to find out which method of vocabulary instruction is more effective, the present study investigated the efficiency of definition-based versus contextualized vocabulary instruction after the two groups received different treatments for a whole educational semester consisting of about 15 sessions. To this aim, two groups of high school students were chosen and assigned to two groups incorporating a contextualized group and a non-context group.. To have a baseline for the comparison of the two groups, both groups were given a vocabulary test at the beginning of the experiment. Table 1 shows the descriptive statistics for this pretest.

TABLE 1

DESCRIPTIVE STATISTICS OF THE PRETEST.

\begin{tabular}{|c|c|c|c|c|c|}
\hline & group & $\mathrm{N}$ & Mean & Std. Deviation & Std. Error Mean \\
\hline \multirow[t]{2}{*}{ Pretest } & decontext & 54 & 13.80 & 3.05 & .41 \\
\hline & context & 53 & 12.48 & 4.31 & .59 \\
\hline
\end{tabular}

As Table 1 reveals the mean scores of the definition-based (decontextualized) and contextualized groups on pre-test are 13.80 and 12.48 respectively. This implies that there is a slight mean difference between the two groups prior to the experiment. Since this is crucial that the two groups have comparable language ability at the beginning of the treatment which enables us to confidently assign them to two groups and begin the experimentation it is necessary to investigate if this mean difference is significant. An independent samples t-test is run to find out about the significance of the difference between the vocabulary knowledge of the two groups (Table 2).

TABLE 2

INDEPENDENT SAMPLES T-TEST OF THE PRETEST

\begin{tabular}{|c|c|c|c|c|c|c|c|}
\hline & & \multicolumn{6}{|c|}{$\begin{array}{l}\text { Levene's Test for Equality of } \\
\text { Variances }\end{array}$} \\
\hline & & $\mathrm{F}$ & Sig. & $\mathrm{t}$ & df & $\begin{array}{l}\text { Sig. (2- } \\
\text { tailed) }\end{array}$ & Mean Difference \\
\hline \multirow[t]{2}{*}{ pretest } & $\begin{array}{l}\text { Equal variances } \\
\text { assumed }\end{array}$ & 4.917 & .029 & 1.835 & 105 & .069 & 1.325 \\
\hline & $\begin{array}{l}\text { Equal variances not } \\
\text { assumed }\end{array}$ & & & 1.829 & 93.613 & .071 & 1.325 \\
\hline
\end{tabular}

As it appears in table 2, the $\mathrm{p}$ value for 93 degrees of freedom is .071 which is less than $\mathrm{p}$ critical value $(\mathrm{p}=.05)$. As a result, it can be concluded that there is no meaningful difference between the mean score of the participants in both contextualized and decontextualized groups. The implication is that the two groups have similar level of abilities as far as their vocabulary knowledge is concerned.

After the treatment, another test of vocabulary was conducted to determine which group had a more significant improvement with regard to their vocabulary knowledge. Having analyzed the data, it was found that the mean score of the decontextualized group $(M=14.48)$ displayed a greater growth than the mean score of the contextualized group $(M=$ 13.20) by a small margin (Table 3 ).

TABLE 3.

DESCRIPTIVE STATISTICS OF THE POSTTEST.

\begin{tabular}{llllll}
\hline & group & $\mathrm{N}$ & Mean & Std. Deviation & Std. Error Mean \\
\hline posttest & decontext & 54 & 14.48 & 3.000 & .408 \\
& context & 53 & 13.20 & 3.555 & .508 \\
\hline
\end{tabular}

As it is shown in the above table, the mean of the decontextualized group is larger than the mean score of the contextualized group. To better understand the relationship, if any, between improvements in vocabulary knowledge 
and the different conditions under which students worked during the term, the post-test results and gain indexes were subjected to further statistical analyses. The comparison of mean values for the different conditions as seen in Tables 3 indicate that there was a difference between the results obtained by the different groups in the post-test. To understand if this mean difference is statistically big enough to prove one method superior over the other, an independent- samples t-test was employed (Table 4)

TABLE 4

INDEPENDENT SAMPLES T-TEST OF THE POSTTEST

\begin{tabular}{llllllll}
\hline & & \multicolumn{2}{l}{$\begin{array}{l}\text { Levene's Test for Equality of } \\
\text { Variances }\end{array}$} & \multicolumn{3}{l}{ t-test for Equality of Means } \\
\cline { 2 - 7 } & $\mathrm{F}$ & Sig. & t & df & $\begin{array}{l}\text { Sig. (2- } \\
\text { tailed) }\end{array}$ & Mean Difference \\
\hline posttest & $\begin{array}{l}\text { Equal variances } \\
\text { assumed } \\
\begin{array}{l}\text { Equal variances not } \\
\text { assumed }\end{array}\end{array}$ & .681 & .411 & 1.969 & 101 & .052 & 1.273 \\
& & & 1.953 & 94.387 & .054 & 1.273 \\
\hline
\end{tabular}

As the table displays, the obtained $\mathrm{p}$ value for 101 degrees of freedom is .052 which is slightly larger than .05 indicating that the null hypothesis of no difference between the mean score of the two groups is rejected. This means that the mean score of the decontextualized group is meaningfully greater than the mean score of the contextualized group which indicates the outperformance of the definition-based learning group. However, this mean difference is not that big to totally reject the efficacy of context-based vocabulary instruction. The findings of the study are discussed in the following section.

\section{DISCUSSION}

There exist conflicting views among language professionals concerning the relative superiority of two approaches to learning second language vocabulary: learning words in context vs. learning words out of context. Convictions are strong among many language professionals that contextualized vocabulary learning is more effective than learning words in lists. For example, Oxford and Scarcella (1994), observe that while decontexutalized learning (word lists) may help students memorize vocabulary for tests, students are likely to rapidly forget words memorized from lists. However, in recent literature dealing with vocabulary acquisition, there can be seen increasing advocacy for explicitly teaching words out of context at an early stage of language acquisition, with more context-based vocabulary learning taking place at later stages of language development (Meara, 1995).

This study compared the efficacy of vocabulary learning non-context, i.e. definition-based, with contextualized word learning in order to shed more light on the best conditions of vocabulary learning. As indicated by the findings, the students in the decontextualized group outperformed the participants in the contextualized group. The contextualized group had many problems facing so many words simultaneously within the text. Most of the time they were frustrated because of the high level of difficulty of their course books. The huge number of the new lexicon put in the text hindered students' abilities in meaning mining and inferencing.

The contextualized group just paid attention to the word for the purpose of comprehension and when the goal was achieved and they could infer the word meaning out of context whether partially or completely correct, they ignored the word itself and also its phonological and morphological features. In other words, vocabularies were attended for the sole purpose of reading comprehension and not for its own sake. As Nation (2002) argues there is a matter of fragility in meaning-focused learning. The amount of vocabulary learning in contextualized group is most of the time lower than the decontextualized group, if it is assumed that both approaches have the same effect of vocabulary learning and retention, still the decontextualized one leads to better results if the factor of time is taken into consideration.

Context seems to be unfortunately unhelpful in getting learners through the right meaning of especially new lexicon. Although both age ranges, i.e., first grade of high school and pre-university level showed the same results for the two situations, the older groups were somehow better at guessing words from context. As Van Daalen-Kapteijns, ElshoutMohr, and de Glopper (2001) propose 'mature readers and readers of high verbal ability use more advanced strategies than younger readers and readers of low verbal ability'. This can be because of their intellectual growth and also the number of words they know, "The more words a learner knows, the more likely it is that he or she will have a greater depth of knowledge for these words" (Qian, 2002, p. 517).

No additional, deliberate analysis of the features of the word or the word-meaning complex need to be undertaken by the contextualized group while meaning inferencing. The student's intention is simply meaning generation for the momentary task of interpretation of the passage at hand. Hence, training on contextualized meaning-guessing can help EFL students to do without English-Persian vocabulary pairs which seem to be inefficient in learning the vocabulary of the English language.

It must be noted that the study was undertaken in an EFL situation, i.e., in Iranian high schools where the students' level are mostly elementary. It is supported by previous research (Nielsen, 2006) that a fundamental vocabulary building is more effective through decontextualized and definition based learning at early stages of language development. 
Apart from all these factors the issue of individual differences should also be taken into consideration. Seeking a single best approach for any kind of teaching suited to all individuals in every situation and even surprisingly across the time cannot be a reasonable and rational strategy. What seems to be more plausible is first of all a good curriculum development based on student needs, which Brown (2009) sees as the first step in every curriculum development, then looking for a 'principled approach' of teaching based on that specific situation.

\section{CONCLUSION}

This study was undertaken by high school English teachers who are teaching at public schools and are concerned about the limited vocabulary knowledge of learners. Given the importance of a sound vocabulary knowledge which is a prerequisite for reading comprehension, the researchers aimed at discovering the best techniques of vocabulary instruction. The next step would be to equip learners with these effective techniques and strategies to enable them to improve their vocabulary knowledge in a short time. Because in some cases learners' vocabulary level is so low that it would be unrealistic to expect them to successfully apply certain vocabulary strategies such as guessing meaning from context for reading comprehension.

The findings of the study showed better results of vocabulary knowledge gain in out of context teaching than the contextualized one which means that the results can be a support of definition-based learning. However, the results should be taken as suggestive rather than definitive, since there are many variables which affect an effective vocabulary learning and teaching principle. Thus, this does not mean that contextualized teaching should be avoided. It seems that the most effective way of teaching in Iranian EFL classes is to start the teaching of the new lesson first by defining the words. This will be a helpful approach to reduce the load of so many new words in the reading text. The next essential step is reading the texts which are related to the vocabularies taught. Melka (1997) argues "only after several occurrences can a word be considered to be a part of the child's lexicon, though reproduction of the item would still be quite impossible" (p. 86). Therefore, spaced repetition and exposure of the new lexicon is of most importance in an EFL situation.

It is noteworthy that context-based and definition-based are neither the only vocabulary learning techniques nor the best techniques that are available for learning. Introducing and having learners practice using a variety of alternative vocabulary learning strategies can be considered an effective way of enabling learners to achieve more effective independent vocabulary learning in the future. Other extra activities that also produce improvement in students' vocabulary knowledge include having them work on different types of vocabulary exercises which require students to process the new word at different cognitive levels once the word has been initially learned through L1 to L2 translation. Extensive reading is also believed to be an excellent activity that improves vocabulary knowledge and increases learner's autonomy. Finally, focusing students' attention on certain words discussed in the class as well as the extrinsic motivation to do well on tests also appear to play a role in vocabulary acquisition. Further research can address the issue of whether context can induce effective learning and long-term retention of new words.

\section{REFERENCES}

[1] Brown, G., \& Yule, G. (1983). Discourse analysis. Cambridge: Cambridge University Press.

[2] Brown, J. D. (2009). Freign and second language needs analysis. In M. H. Long, \& C. J. Doughty, (Eds.), The handbook of language teaching (pp. 269-287). Retrieved June 10, 2011, from http://www.blackwellpublishing.com

[3] Hulstijn, J. H. (2001). Intentional and incidental second language vocabulary learning: a reappraisal of elaboration, rehearsal and automaticity (ed.), In P. Robinson, Cognition and second language instruction (pp. 258-286). Cambridge: Cambridge University Press.

[4] Laufer, B. (2001). Reading, word - focused activities and incidental vocabulary acquisition in a second language. Prospect, 16(3), 44-54.

[5] Laufer, B., \& Shmueli, K. (1997). Memorizing new words: Does teaching have anything to do with it? RELC Journal, 28(1), 89-108.

[6] Levenston, E. A. (1979). Second language vocabulary acquisition: issues and problems. Interlanguage Studies Bulletin, 4 (2), 147-160.

[7] Llinares, G., Leiva, B., Cartaya, N., \& Louis, R. S. (2008). Acquisition of L2 vocabulary for effective reading: testing teachers' classroom practice. The Reading Matrix, 8(2), 55-69.

[8] Meara, P. (1980). Vocabulary acquisition: A neglected aspect of language learning. Language Teaching and Linguistics, 15, 221-246.

[9] Meara, P. (1995). 'The importance of an early emphasis on L2 vocabulary.' The Language Teacher 19(2), 8-10.

[10] Melka, F. (1997). Receptive vs. productive aspects of vocabulary. In N. Schmitt \& M. McCarthy (Eds.), Vocabulary: Description, acquisition and pedagogy (pp. 84-102). Cambridge: Cambridge University Press.

[11] Mondria, J.-A. (2003). The effects of inferring, verifying, and memorizing on the retention of L2 word meanings: An Experimental Comparison of the "Meaning-Inferred Method" and the "Meaning-Given Method". SSLA, 25, 473-499.

[12] Nagy, w. (1997). On the role of context in first- and second-language vocabulary learning. In N. Schmidt, \& M. McCarthy (Eds.), Vocabulary: Description, acquisition and pedagogy (pp. 64-83). Cambridge University Press.

[13] Nassaji, H. (2006). The Relationship Between Depth of Vocabulary Knowledge and L2 Learners' Lexical Inferencing Strategy Use and Success. The Canadian Modern Language Review, 61(1), 107-134.

[14] Nation, I. S. (2001). Learning vocabulary in another language. Cambridge: Cambridge University Press. 
[15] Nation, P. (2002). Best Practice in Vocabulary Teaching. In J. C. Richards, \& W. A. Renandya (Eds.). Methodology in Language Teaching (pp. 267-272). New York: Cambridge University Press.

[16] Nielsen, B. (2006). A review of research into vocabulary learning and acquisition. Retrieved May 15, 2012, from http://www.kushiro-ct.ac.jp/library/kiyo/kiyo36/Brian.pdf.

[17] Paribakht, S., and Wesche, M. (1999), Reading and incidental L2 vocabulary acquisition: An introspective study of lexical inferencing. Studies in Second Language Acquisition, 21, 195-224.

[18] Oxford, R.L. \& Scarcella, R.C. (1994). 'Second language vocabulary learning among adults: State of the art in vocabulary instruction.' System 22(2), 231-43.

[19] Qian, D. D. (2002). Investigating the Relationship Between Vocabulary Knowledge and Academic Reading Performance: An Assessment Perspective. Language Learning, 52, 513-536.

[20] Shahrzad, A., \& Derakhshan, A. (2011). The Effect of Instruction in Deriving Word Meaning on Incidental Vocabulary Learning in EFL Context. World Journal of English Language. 1(1), 68-79.

[21] Snellings, P., Gelderen, A. v., \& Glopper, K. d. (2002). Lexical retrieval: An aspect of fluent second language production that can be enhanced. Language Learning, 52, 723-754.

[22] Van Daalen-Kapteijns, M., Elshout-Mohr, M., \& Glopper, K. d. (2001). Deriving the meaning of unknown words from multiple contexts. Language Learning, 51 (1) 145-181.

[23] Zaid, M. A. (2009). A Comparison of Inferencing and Meaning-guessing of New Lexicon in Context versus Non-context Vocabulary Presentation. The Reading Matrix, 9(1), 56-66.

Seyyed Mohammad Reza Amirian is an assistant professor of TEFL at Hakim Sabzevari University, Iran. He got his PhD in TEFL from the University of Tehran. He has published some articles in leading journals and has presented in both national and international conferences. His research interest includes test fairness, differential item functioning, teaching and testing language skills, and CALL.

Sakine Momeni is an MA student of TEFL at Hakim Sabzevari University, Iran. She is a teacher at public high schools. She is currently working on her MA thesis. 